\title{
Editorial: Manifesto Commentaries
}

\author{
Ed Ferrari* \\ Sheffield Hallam University
}

I am delighted to introduce this Special Issue of PPP which offers a series of policy commentaries related to the main manifestos published by political parties in advance of next week's UK General Election.

PPP has now long established itself as a leading forum for policy relevant research related to our concerns around people and place, and policies that govern their life chances and outcomes. Our focus is particularly on social and economic disadvantage and how this can be overcome.

All the main political parties recognise in their distinctive ways the enormity of the social, economic and cultural divides that have emerged within the UK. It is right that we subject their manifesto commitments, and the narratives that support these, to scrutiny.

That is what this Special Issue seeks to do. In it we have contributions from leading scholars on topics such as migration policy, government spending and austerity, education, housing and others. These are all areas of public policy that indelibly characterise the debate within our national politics and where the parties' commitments - and delivery - around policy can serve to make a significant impact on outcomes.

I hope you enjoy this Special Issue.

* Correspondence address: Professor Ed Ferrari, Director, Centre for Regional Economic and Social Research (CRESR), Sheffield Hallam University, Howard Street, Sheffield, S1 1WB. Email: e.ferrari@shu.ac.uk 